Article

\title{
Factors related to reduction in the consumption of fast food: application of the theory-based approaches
}

\author{
Zeinab Jalambadani, ${ }^{1}$ Gholamreza Garmaroudi, ${ }^{2}$ Mehdi Yaseri, ${ }^{3}$ Mahmood Tavousi,4 \\ Korush Jafarian 5 \\ ${ }^{1}$ Faculty of Health, Tehran University of Medical Sciences; ${ }^{2}$ Department of Health Education and \\ Promotion, Faculty of Health, Tehran University of Medical Sciences; ${ }^{3}$ Department of \\ Epidemiology and Biostatistics, School of Public Health, Tehran University of Medical Sciences; \\ ${ }^{4}$ Health Metrics Research Center, Iranian Institute for Health Sciences Research, ACECR, Tehran; \\ ${ }^{5}$ Department of Nutrition and Biochemistry, School of Nutritional Sciences and Dietetics, Tehran \\ university of Medical Sciences, Tehran, Iran
}

Significance for public health

The Ministries of Education and Public Health should cooperate in supporting the below-mentioned formal and non-formal school, family and community nutritional education and activities. Lastly, the Ministry of Public Health should conduct programmes with restaurant owners on healthy Iranian food and its hygienic presentation and promotion, to enhance their ability to compete with fast-food restaurants.

\section{Abstract}

Background. The Trans-Theoretical model (TTM) and Theory of Planned Behaviour (TPB) may be promising models for understanding and predicting reduction in the consumption of fast food. The aim of this study was to examine the applicability of the Trans-Theoretical model (TTM) and the additional predictive role of the subjective norms and perceived behavioural control in predicting reduction consumption of fast food in obese Iranian adolescent girls.

Materials and methods. A cross sectional study design was conducted among twelve randomly selected schools in Sabzevar, Iran from 2015 to 2017. Four hundred eighty five randomly selected students consented to participate in the study. Hierarchical regression models used to predict the role of important variables that can influence the reduction in the consumption of fast food among students. using SPSS version 22.

Results. Variables Perceived behavioural control $(\mathrm{r}=0.58$, $\mathrm{P}<0.001)$, Subjective norms $(\mathrm{r}=0.51, \mathrm{P}<0.001)$, self-efficacy $(\mathrm{r}=0.49, \mathrm{P}<0.001)$, decisional balance (pros) $(\mathrm{r}=0.29, \mathrm{P}<0.001)$, decisional balance (cons) $(\mathrm{r}=0.25, \mathrm{P}<0.001)$, stage of change $(\mathrm{r}=0.38, \mathrm{P}<0.001)$, were significantly and positively correlated while experiential processes of change $(\mathrm{r}=0.08, \mathrm{P}=0.135)$ and behavioural processes of change $(r=0.09, P=0.145)$, were not significant.

Conclusions. The study demonstrated that the TTM (except the experiential and behavioural processes of change) focusing on the perceived behavioural control and subjective norms are useful models for reduction in the consumption of fast food.

\section{Introduction}

In Iran, the trend of obesity and overweight is similar to the global trend, and the condition is worse in women in comparison with men. ${ }^{1-3}$ Many risk factors have been identified in relation to the prevalence of obesity in children and adolescents. ${ }^{4}$ These factors include: Lack of physical activity, unhealthy food consumption patterns, such as high consumption of processed foods, consumption of carbonated beverages, long-term use of TV and computers, and environmental impacts and family meals. Among the factors mentioned, unhealthy diet, especially fast food, acts as a prominent factor for obese and overweight kids. ${ }^{5}$ The use of unhealthful foods has increased. According to one study, 28 percent of teens consume snacks from fast food to high levels of the use of medium. ${ }^{6}$ Fast food consumption in Iranian teenagers was 20 percent in $2016 .{ }^{7}$ Fast food represents one of the factors threatening the health of people and the amount of food consumed outside the home. ${ }^{3,8}$ According to the WHO, fast food consumption is thriving in many societies and has a significant impact on public health, especially in developing countries. ${ }^{9,10}$

Several theories about the role of beliefs and ideas of young people have been proposed about the side effects of fast food consumption. ${ }^{11}$ In the meantime, the socio-cognitive theory provides a good framework for understanding this. These theories include the theory of planned behaviour, health belief model, social cognitive theory and the Trans-Theoretical Model (TTM). ${ }^{12}$ TTM is widely used in different populations for nutritional treatment. ${ }^{13}$ TTM is a regular and systematic framework to analyse issues related to the decisions to provide a behaviour. ${ }^{12}$ Lach et al. ${ }^{14}$ and Jiang et al. ${ }^{15}$ emphasized health education programmes while talking about the usefulness of the TTM as a practical theory. An advantage of TTM is that healthcare practitioners are able to treat individuals while they are in different phases of readiness to make changes in their health behaviours. ${ }^{12}$ TTM has four constructs: Stage of change, decisional balance (pros and cons), processes of change (the experiential and behavioural processes), and self-efficacy. ${ }^{3,16}$ Despite the success of TTM, there is still a ratio of unaccounted variance and so, ${ }^{16}$ further predictors have been investigated that may increase the power of TTM. ${ }^{12}$ An important guideline when designing interventions around the TTM is to consider relationships of the TTM variables with constructs from other established health behaviour theories such as Theory of Planned Behavior (subjective norm and perceived behavioural control) 
may be important predictors for reduction in the consumption of fast food. ${ }^{16-18}$ Subjective norms and perceived behavioural controls may be important predictors of the reduction in the consumption of fast food. ${ }^{16,18,19}$ Subjective norms include what other people think and how other people behave ${ }^{13}$ Perceived behavioural control include factors that may facilitate completion of the behaviour (such as resources and opportunities). ${ }^{20}$ Because of the complementary nature of these two models, research has begun to use TTM and TPB (perceived behavioural control, subjective norms) to get a richer understanding of behaviour for reduction in the consumption of fast food in obese Iranian adolescent girls in Sabzevar, Iran from 2015 to 2017.

\section{Materials and Methods}

\section{Study design and setting}

A cross sectional design was employed between March 2015 and 2017 among students from Sabzevar, Iran. At the time of the study, there were 57 schools in the Sabzevar, twelve schools were randomly selected. Using lottery methods for the study with a total of students registered. Culturally similar students were the setting for the study. Obese Iranian adolescent girls ranged in age from 15 to 18 years. Students $(n=485)$ were enrolled. Ethical approval for this study was gained from the research ethics committee at Tehran University of Medical Sciences with the number of (IR.TUMS.REC.1394.760) in 2015. An informed consent was obtained from all of the participants and parents.

\section{Inclusion criteria}

1. Adolescent girls between $15-18$ years 2 . BMI values $\geq 85$ th (CDC) 3 . No diets 4 . All of the samples participated willingly and voluntarily in this study. (Voluntary consent) 5. Being Iranian 6. Fast food (Sausage, sandwich, pizza, hamburgers, hot dogs, French fries) consumption once a week.

\section{Exclusion criteria}

1. Sick students. 2. Incomplete questionnaires. 3. Physical activity because of confounding effect. Students completed the measures in a classroom setting.

\section{Sample size}

The sample size was calculated using the formula for cross- sectional study with 0.05 margin of error, $95 \%$ confidence level, 1.5 design effect and additional $15 \%$ non response rate. ${ }^{21,22}$ It was calculated that a sample of 485 students.

\section{Demographic variables}

Demographic variables included, age, grade, level of education of the mother and father (illiterate, primary, guidance, school, high school, associate, B.S, M.S, PhD), job of mother and father (house wife, government employed, private sector employed, unemployed), number of members child, family residence status (Rent Personal), height, weight and BMI(Weight $(\mathrm{kg}) /$ height $\left.(\mathrm{m})^{2}\right)$ measured. Trained persons performed measurement of height and weight based on the protocol of WHO at the residence of the participants. Measurement of weight was performed in terms of $\mathrm{kg}$, using a digital balance, with an error of less than 100 grams, and of height was done using a ribbon meter and in terms of meter.

Self administered structured questionnaire, adapted from similar previous studies, questionnaires provided at Tehran University of Medical Sciences based on TTM and TPB ${ }^{23}$ The questionnaires pilot was tested on 20 students. All questionnaires CVI (Content Validity Index) and CVR (Content Validity Ratio) values were higher than 0.75 and 0.62 . Face validity were considered to be suitable with respect to 18 of expert panel members (Table 1). ${ }^{24}$

\section{Stages of behaviour change}

The TTM consists of five stages of change (pre-contemplation, contemplation, preparation, action, maintenance) represent the temporal, motivational, and consistency of behaviour change. ${ }^{25}$ To five stages of change the regard to the following questions.

1- I have not reduce fast food consumption and I have not thought about it (yes - no).

2- I have not reduce fast food consumption, but I have thought about it (yes - no).

3- I have not reduce fast food consumption, but I am planning to do so within one month (yes - no).

4- Now it is less than 6 month since I have reduced my consumption of fast food (yes - no).

5- Now it is more than 6 months since I have reduced my consumption of fast food (yes - no).

The answer yes reveals that the participant is in that stage and the answer no reveals that she is in other stages.

Questions ranging from pre-contemplation $(=1)$, contemplation $(=2)$, preparation $(=3)$, action $(=4)$ and maintenance $(=5)$.

Table 1. Psychometric properties of the transtheoretical model constructs, subjective norm, perceived behavioural control.

\begin{tabular}{lcc} 
Measures & Content validity index & Content validity ratio \\
Stage of change Ques & 0.92 & 0.90 \\
Self-efficacy Ques & 0.98 & 0.97 \\
\hline Pros Ques & 0.83 & 0.86 \\
Decisional balance (pros) Ques & 0.83 & 0.82 \\
\hline Decisional balance (cons) Ques & 0.81 & 0.85 \\
Experiential processes of change Ques & 0.88 & 0.84 \\
\hline Behavioral processes of change Ques & 0.82 & 0.90 \\
Subjective norm Ques & 0.90 & 0.88 \\
\hline Perceived behavioral control Ques & 0.94 & 0.80 \\
Reduction in the consumption of fast food Ques & 0.89 & 0.94 \\
\hline
\end{tabular}




\section{Self-efficacy}

Self-efficacy as the confidence of persons on their ability for reduction in the consumption of fast food ${ }^{26}$ Self-efficacy includes confidence and temptation. ${ }^{27}$ Confidence is described as the belief that one is able to engage in a healthy behaviour across multiple contexts while temptation is described as one's temptation or urge to engage in an unhealthy behaviour across multiple contexts. ${ }^{27}$

In this research, eight questions were designed. The stem of all questions began with the phrase How much you are confidence that you can. The answers to the questions were designed in the form of 5 optional Likert scale (completely confidences $=5$, not confidence at all $=1$ ).

\section{Decisional balance}

The TTM consists of decisional balance construct assesses the perceived barriers (cons) and benefits (pros) associated with the adoption of healthy behaviour. ${ }^{25}$ Decisional balance for reducing fast food consumption was assessed using a questionnaire with 8 questions. The questions on assessing pros including delight arisen from fast food consumption in dietary (one question), positive effects on bodily fitness (one question), positive effects of comfort sleep (one question), positive effects on longevity (one question), positive effects on increasing resistance toward difficulties (one question). The questions on assessing cons including: Feel uncomfortable without fast food (one question), my life would be dull and boring without fast food, (one question), lack of entertainment (one question), much time to prepare healthy foods is necessary without fast food (one question).

The answers to the questions were designed in the form of 5 optional Likert scale (very much $=5$, very little $=1$ ).

\section{Processes of change}

The experiential approaches are most effective when individuals have not yet changed their behaviour (pre-contemplation and contemplation stages), whereas behavioural strategies are more appropriate when individuals have initiated or are attempting to maintain new behaviours (action or maintenance stages). ${ }^{12}$

The questionnaires (PCS) for reduction in the consumption of fast food contain 30 items that measure experiential and behavioural processes of change. The items had moderate internal consistency: consciousness raising (0.89), self-liberation (0.78), social liberation (0.79), counter conditioning (0.88), stimulus control (0.78), helping relationship (0.80), and dramatic relief $(0.80)$, self-reevaluation $(0.86)$, environmental reevaluation $(0.87)$, reinforcement management $(0.86)$.

The questionnaires were consisted of questions experiential processes of change (consciousness raising (3 items), helping relationship (3 items), self liberation (3 items), dramatic relief (3 items), environmental reevaluation (3 items).

Behavioural processes of change (self-reevaluation (3 items), social liberation (3 items), reinforcement management (3 items), stimulus control (3 items), counter conditioning ( 3 items), and assessed ranging from disagree strongly to agree strongly +1 to 5 .

\section{Reduction in the consumption of fast food}

This scale had four items, how often do you eat fast food in 7 days? What time would you normally buy fast food? How often do you eat fast food in 30 days? How often do you consume fast food at school?

\section{Subjective norm}

This scale had four items; direct subjective norm assessed ranging from disagree strongly to agree strongly +1 to 5 . The items had high internal consistency (Cronbach's alpha $=0.90$ ).

\section{Perceived behavioural control}

Perceived behavioural control include external control factors. This scale had two items; PBC assessed ranging from disagree strongly to agree strongly $(+1$ to +5$)$. The items had high internal consistency (Cronbach's alpha $=0.95$ ).

\section{Anthropometric}

Trained persons performed measurement of height and weight based on the protocol of world health organization at the residence of the participants. measurement of weight was performed in terms of $\mathrm{kg}$, using a digital balance, with an error of less than 100 grams, and of height was done using a ribbon meter and in terms of meter.

\section{Statistical analysis}

The analysis was carried out by SPSS software version 22 . Descriptive statistics including mean and deviation frequency were used to describe demographic information of research samples. The correlation coefficient of Pearson were used to determine correlation and between TTM variables and subjective norms, perceived behavioural control. Using a hierarchical regression was conducted. The level of significance of $\mathrm{P}<0.05$ was considered for all tests.

\section{Results}

The mean \pm standard deviation for age $(16.36 \pm 0.70)$, for weight (66.46 \pm 4.34$)$, height (158.69 \pm 3.04$)$, BMI (1.24 \pm 0.42$)$, number of children in family $(2.59 \pm 0.75)$ (Table 2). Pre-contemplation $(35.7 \%)$, contemplation $(37.1 \%)$, preparation $(8.9 \%)$, action $(9.3 \%)$, maintenance $(9.1 \%)$ of the population enters into each stage.

The means and standard deviations for the processes of change were Behavioural; Self-liberation $(\mathrm{M}=13.99, \mathrm{SD}=3.24)$. Counterconditioning $(M=10.26, S D=2.59)$. Stimulus control $(M=9.79$, $\mathrm{SD}=6.36)$. Cognitive; Consciousness raising $(\mathrm{M}=10.21, \mathrm{SD}=3.20)$. Social liberation $(M=9.91, S D=6.43)$. Dramatic relief $(M=11.85$, $\mathrm{SD}=3.45)$. Environmental re-evaluation $(\mathrm{M}=7.11, \mathrm{SD}=2.06)$. Reinforcement management $(\mathrm{M}=9.47, \mathrm{SD}=2.07)$. Self re- evaluation $(\mathrm{M}=6.28, \mathrm{SD}=2.44)$. Helping relationships $(\mathrm{M}=12.28$, $\mathrm{SD}=2.06)$.

\section{Relationships between constructs}

The correlation coefficient of Pearson was used to determine correlation between constructs from the TTM and subjective norm and perceived behavioural control. Perceived behavioural control

Table 2. Mean of age, weight, height, body mass index, the number of children.

\begin{tabular}{lc} 
Variable & Mean \pm SD \\
Age (year) & $16.36 \pm 0.70$ \\
Weight $) \mathrm{kg}$ ) & $66.46 \pm 4.34$ \\
\hline Height (cm) & $158.69 \pm 3.04$ \\
Body mass index (BMI) & $1.24 \pm 0.42$ \\
\hline Number of children in family & $2.59 \pm 0.75$ \\
\hline
\end{tabular}


$(\mathrm{r}=0.58, \mathrm{P}<0.001)$, subjective norms $(\mathrm{r}=0.51, \mathrm{P}<0.001)$, stage of change $(\mathrm{r}=0.38, \mathrm{P}<0.001)$, self-efficacy $(\mathrm{r}=0.49, \mathrm{P}<0.001)$, decisional balance (pros) $(\mathrm{r}=0.29, \mathrm{P}<0.001)$, decisional balance (cons) $(\mathrm{r}=0.25, \mathrm{P}<0.001)$, were significantly and strongly correlated to reduction in the consumption of fast food. The experiential processes of change $(\mathrm{r}=0.08, \mathrm{P}=0.135)$, the behavioural processes of change $(\mathrm{r}=0.09, \mathrm{P}=0.145)$, were not significantly (Table 3$)$. The correlation coefficient of Pearson was used to determine correlation between constructs from the processes of change (Table 4).

Hierarchical regression was performed, with predictor variable(s) entered in each step as determined by the researcher. Stage of change, the experiential processes of change and the behavioural processes, decisional balance (pros, cons), self-efficacy were entered in the first step. Stage of change accounted $21 \%$ of variance reduction in the consumption of fast food $(\beta=0.21$, $\mathrm{P}<0.001, \mathrm{t}=2.25$ ). The processes of change (experiential and behavioural) accounted $1 \%$ of variance reduction in the consumption of fast food $(\beta=0.01, \mathrm{P}=0.13, \mathrm{t}=0.14)$. The decisional balance (pros and cons) accounted $19 \%$ of variance reduction in the consumption of fast food $(\beta=0.19, \mathrm{P}<0.001, \mathrm{t}=3.14)$. The self-efficacy accounted $41 \%$ of variance $(\beta=0.41, \mathrm{P}<0.001, \mathrm{t}=2.92)$. The overall regression, including 4 predictors, was statistically significant, $\left(\mathrm{R}=0.63, \mathrm{R}^{2}=0.39, \mathrm{~F}=24.16, \mathrm{P}<0.001\right)$.

The statistically significant predictors that emerged in the second step were stage of change accounted $22 \%$ of variance reduction in the consumption of fast food $(\beta=0.22, \mathrm{P}<0.001, \mathrm{t}=2.37)$.
The processes of change (experiential and the behavioural) accounted $5 \%$ of variance reduction in the consumption of fast food $(\beta=0.05, \mathrm{P}=0.13, \mathrm{t}=0.98)$. The decisional balance (pros and cons) accounted $51 \%$ of variance reduction in the consumption of fast food. $(\beta=0.51, \mathrm{P}<0.001, \mathrm{t}=5.43)$. The self-efficacy accounted $52 \%$ of variance $(\beta=0.52, \mathrm{P}<0.001, \mathrm{t}=5.91)$. Subjective norms accounted for $53 \%$ of variance $(\beta=0.53, \mathrm{P}<0.001, \mathrm{t}=6.01)$. Perceived behavioural control accounted $58 \%$ of variance $(\beta=0.58$, $\mathrm{P}<0.001, \mathrm{t}=6.19$ ). The strongest predictor for reduction the consumption of fast food was perceived behavioural control. The overall regression, including 6 predictors, was statistically significant $\left(\mathrm{R}=0.83, \mathrm{R}^{2}=0.69, \mathrm{~F}=58.64, \mathrm{P}<0.001\right)$ (Table 5).

\section{Discussion}

The current study was designed to understand and predict reduction the consumption of fast food using the Transtheoretical Model of behaviour change as well as the Theory of Planned Behavior (perceived behavioural control, subjective norms).

Although research has yet to examine how the TTM is related to the TPB, the results of current study lend support to this alternative examination of the models to predict behaviours. Hierarchical regression analyses revealed stages of change, decisional balance (pros and cons), perceived behavioural control, subjective norms, self-efficacy significantly predicted reduction the consumption of

Table 3. Partial correlations (Pearson's r) among the components of TTM constructs and perceived behavioural control, subjective norm.

Constructs Reduction Experiential Behavioural Self-efficacy Decisional Decisional Subjective Perceived Stage
in the processes of processes
consumption change of change
of fast food

Reduction in the consumption of fast food

\begin{tabular}{|c|c|c|c|c|c|c|c|c|c|}
\hline Experiential processes of change & 0.08 & 1 & & & & & & & \\
\hline Behavioural processes of change & 0.09 & $0.48^{* *}$ & 1 & & & & & & \\
\hline Self-efficacy & $0.49 * *$ & $0.19 *$ & $0.18^{*}$ & 1 & & & & & \\
\hline Decisional balance (pros) & $0.29 * *$ & 0.04 & $0.09 *$ & $0.15^{*}$ & 1 & & & & \\
\hline Decisional balance (cons) & $0.25^{* *}$ & 0.06 & $0.10^{*}$ & $0.12^{*}$ & $0.14^{*}$ & 1 & & & \\
\hline Subjective norm & $0.51^{* *}$ & 0.08 & $0.18^{* *}$ & $0.43^{* *}$ & $0.28^{* *}$ & $0.23^{*}$ & 1 & & \\
\hline Perceived behavioural control & $0.58^{* *}$ & 0.08 & $0.28^{* *}$ & $0.33^{* *}$ & $0.28^{* *}$ & $0.32^{* *}$ & $0.26^{*}$ & 1 & \\
\hline Stage of change & $0.38 * *$ & 0.04 & 0.06 & $0.31^{* *}$ & 0.08 & $0.28^{* *}$ & $0.33^{* *}$ & $0.23 * *$ & 1 \\
\hline
\end{tabular}

${ }^{*} \mathrm{P}<0.001 ;{ }^{*} \mathrm{P}<0.05$.

Table 4. Correlations the processes of change.

\begin{tabular}{|c|c|c|c|c|c|c|c|c|c|c|}
\hline Processes of change & CR & SL & CC & SC & HR & DR & SL & SR & ER & RM \\
\hline Consciousness raising & 1 & & & & & & & & & \\
\hline Self-liberation & 0.04 & 1 & & & & & & & & \\
\hline Counter-conditioning & $0.32 *$ & 0.36 & 1 & & & & & & & \\
\hline Stimulus control & 0.06 & 0.56 & 0.26 & 1 & & & & & & \\
\hline Helping relationships & $0.22 *$ & 0.04 & 0.16 & 0.20 & 1 & & & & & \\
\hline Dramatic relief & 0.23 & 0.41 & 0.09 & 0.20 & 0.14 & 1 & & & & \\
\hline Social liberation & 0.19 & 0.16 & 0.09 & 0.19 & 0.31 & 0.03 & 1 & & & \\
\hline Self re-evaluation & $0.32 *$ & 0.27 & 0.22 & $0.31^{*}$ & 0.29 & $0.42 *$ & 0.31 & 1 & & \\
\hline Environmental re-evaluation & 0.10 & 0.23 & 0.03 & 0.24 & 0.39 & $0.39 *$ & 0.19 & 0.14 & 1 & \\
\hline Reinforcement management & $0.46^{*}$ & 0.29 & $0.33^{*}$ & 0.20 & $0.39 *$ & 0.10 & $0.51^{*}$ & $0.38^{*}$ & 0.03 & 1 \\
\hline
\end{tabular}

${ }^{*} \mathrm{P}<0.001$. Consciousness Raising, CR; Self-Liberation, SL; Counter-Conditioning, CC; Stimulus Control, SC; Helping Relationships, HR; Dramatic Relief, DR; Social Liberation, SL; Self Re-evaluation, SR; Environmental Re-evaluation, ER; Reinforcement Management, RM. 
fast food. These results do not suggest that one model better in reduction the consumption of fast food, but that prediction of reduction the consumption of fast food is improved with these models in conjunction. Perceived behavioural control was the most significant predictor of reduction the consumption of fast food. The results of current study are not consistent with the study of Armitage and Conner (2010), it was worth differentiating between the external control factors (PBC) and internal self-efficacy, as the internal factors appeared to play a much stronger part in influencing intentions, other studies have supported the premise that selfefficacy is predictive of behaviour. ${ }^{28,29}$ This difference may be related to the type of behaviours measured. Subjective norms were found to be a significant predictor in reduction the consumption of fast food.

Environmental factors, such as associations with social or support groups who promote reduction the consumption of fast food may also provide positive effects. Similarly, it should be noted that family and friends are also likely to act as powerful groups as this is important information for individuals who wish reduction the consumption of fast food. This suggests that social influence and the need to comply with group norms in particular, influence fast food consumption. It is worth noting that the earlier qualitative study identified perceptions of being overweight as a particular source of fear of negative evaluation. However, neither the opinions held by health experts nor the behaviour modelled by significant others were significantly predictive.

These results are consistent with research where subjective norms predicted intention, and was significant, ${ }^{30}$ this would suggest that adolescent girls are more concerned about social normative influences than their own processes of change towards reduction the consumption of fast food. In another study found subjective norms to be more predictive of intention when looking at safety helmet use and suggested that subjective norms are more likely than attitude to predict intention in health behaviours that could affect the health of others or in behaviours that may be performed publicly. ${ }^{20}$ This would be particularly applicable in the area of reduction the consumption of fast food, as these behaviours are both likely to affect the health of others and may be performed in front of people.
Self-efficacy was a predictor of consumption reduction of fast food. Studies show that food and nutrition related self-efficacy in adolescents with food choices healthy diet and behaviour. ${ }^{31,32}$

The decisional balance was significant in our study. The results of the study are not consistent with the following studies ${ }^{33}$ The perception and endorsement of the pros of changing may be a powerful change strategy for moving individuals in the stages of change. The pros may be more disposed to change than the cons because the pros more sensible and immediate whereas a reduction in the cons requires longer-term maintenance.

The experiential and behavioural processes of change were not found to be significantly predictive of reduction the consumption of fast food. Processes of change are the strategies that people use to apply transition from one stage to another. Processes of change in previous studies were important predictors of adoption and maintenance behave ${ }^{34,35}$ Processes of change in children and adolescents should include increasing knowledge of hazards and diseases caused by the consumption of fast food in the short and long term of multi-dimensional illness.

In other words, although participants appeared to be aware that the longer-term consequences of frequent fast-food consumption were likely to be negative, this knowledge did not have a significant impact on fast food consumption rates. Similarly, if adolescents perceive that they generally eat unhealthily, this may allow

\section{Conclusions}

Overall, the results from our study are congruent with the previous findings in western countries and therefore, this study supports the external validity of TTM. In summary, the TTM and TPB (subjective norm and perceived behavioural control) is a logical and coherent explanation of behaviour in Iranian students. Future studies should explore the effects of reduction in the consumption of fast food developed in reference to the TTM and TPB among Iranian studies using randomized controlled trials.

The most important limitation of this study is that despite the use of self-report questionnaire due to the nature of the question-

Table 5. Hierarchical regression of Stage of change, Processes of change, Self-efficacy, Decisional balance, subjective norms, perceived behavioural control into reduction in the consumption of fast food.

\begin{tabular}{|c|c|c|c|c|c|}
\hline Variables & $\beta$ & $\mathrm{t}$ & $\mathbf{R}$ & $\mathbf{R}^{2}$ & F \\
\hline \multicolumn{6}{|c|}{ Step 1} \\
\hline Stage of change & 0.21 & $2.25^{*}$ & 0.63 & 0.39 & $24.16^{* *}$ \\
\hline Experiential processes of change & 0.01 & 0.14 & & & \\
\hline Behavioural processes of change & 0.01 & 0.14 & & & \\
\hline Decisional balance (pros) & 0.19 & $3.14^{* *}$ & & & \\
\hline Decisional balance (cons) & 0.19 & $3.14 * *$ & & & \\
\hline Self-efficacy & 0.41 & $2.92^{* *}$ & & & \\
\hline \multicolumn{6}{|c|}{ Step 2} \\
\hline Stage of change & 0.22 & $2.37^{*}$ & 0.83 & 0.69 & $58.64^{* *}$ \\
\hline Experiential processes of change & 0.05 & 0.98 & & & \\
\hline Behavioural processes of change & 0.05 & 0.98 & & & \\
\hline Decisional balance (pros) & 0.51 & $5.43^{* *}$ & & & \\
\hline Decisional balance (cons) & 0.51 & $5.43^{* *}$ & & & \\
\hline Self-efficacy & 0.52 & $5.91^{* *}$ & & & \\
\hline Subjective norm & 0.53 & $6.01^{* *}$ & & & \\
\hline Perceived behavioural control & 0.58 & $6.19 * *$ & & & \\
\hline
\end{tabular}


naire responses it is debatable validity. These data have been taken from a descriptive study and their power is restricted in drawing conclusion of the predictors of behaviour.

Correspondence: Gholamreza Garmaroudi, Department of Health Education and Promotion, Faculty of Health, Tehran University of Medical Sciences, Tehran, Iran.

Tel.: +98.2188989128 / 09153714973 - Fax: +98.2188989129

E-mail: garmaroudi@tums.ac.ir

Key words: behavior change; obesity; overweight; student.

Acknowledgments: this study was a part of the PhD dissertation project,

which was supported by Tehran University of Medical Sciences, Tehran, Iran.

Authors are thankful for supporting the study by Tehran University of

Medical Sciences, Tehran, Iran. Our gratitude and thanks is also extended to all managers and students.

Contributions: ZJ had participated in data collection and analysis and drafted the paper; GG, MT, MY, KJ designed and supervised the study and edited the draft of the paper.

Conflict of interest: the authors declare no potential conflict of interest.

Received for publication: 21 February 2017.

Accepted for publication: 13 July 2017.

(C) Copyright Z. Jalambadani et al., 2017

Licensee PAGEPress, Italy

Journal of Public Health Research 2017;6:832

doi:10.4081/jphr.2017.832

This work is licensed under a Creative Commons Attribution NonCommercial 4.0 License (CC BY-NC 4.0).

\section{References}

1. Azizi F, Azadbakht L, Mirmiran P. Trends in overweight, obesity and central fat accumulation among Tehranian adults between 1998-1999 and 2001-2002: Tehran lipid and glucose study. Ann Nutr Metab 2005;49:3-8.

2. Janghorbani M, Amini M, Willett WC, et al. First nationwide survey of prevalence of overweight, underweight, and abdominal obesity in Iranian adults. Obesity 2007; 15:2797-808.

3. Mousavi A, Shams M, Toori MA, Mousavizadeh A, Morowatisharifabad MA. Behavioral stages of change in calorie balanced dietary intake; effects of decisional balance and self-efficacy in obese and overweight women. Nautilus 2014;128:12-21.

4. Franz MJ, VanWormer JJ, Crain AL, et al. Weight-loss outcomes: a systematic review and meta-analysis of weight-loss clinical trials with a minimum 1-year follow-up. J Am Diet Assoc 2007;107:1755-67.

5. Jackson P, Romo MM, Castilo MA, Castillo-Durán D. [Junk food consumption and child nutrition. utritional anthropological analysis]. Rev Med Chil 2004;132:1235-42. [Article in Spanish]

6. Kelishadi R, Ardalan G, Gheiratmand R, et al. [Thinness, overweight and obesity in a national sample of Iranian children and adolescents: CASPIAN Study]. Child Care Health Dev 2008;34:44-54. [Article in Persian].

7. Kelishadi R, Mozafarian N, Qorbani M, et al. Association between screen time and snack consumption in children and adolescents: The CASPIAN-IV study. J Pediatr Endocrinol Metabolism 2017;30:211-9.

8. Azizy F. Methods learning in medical siences. Tehran: Ramin; 1992.
9. Dymytrenko M. Determinants and correlates of junk food consumption among students of the:National University of KyivMohyla Academy; 2009.

10. Pereira MA, Kartashov AI, Ebbeling CB, et al. Fast-food habits, weight gain, and insulin resistance (the CARDIA study): 15-year prospective analysis. Lancet 2005;365:36-42.

11. Rouhani MH, Mirseifinezhad M, Omrani N, et al. Fast food consumption, quality of diet, and obesity among Isfahanian adolescent girls. J Obes 2012;2012:597924.

12. Prochaska JJ, Nigg CR, Spring B, et al. The benefits and challenges of multiple health behavior change in research and in practice. Prev Med 2010;50:26-9.

13. Ajzen I. The theory of planned behaviour: reactions and reflections. Psychology Health 2011;26:1113-27.

14. Lach HW, Everard KM, Highstein G, Brownson CA. Application of the transtheoretical model to health education for older adults. Health Promot Pract 2004;5:88-93.

15. Jiang G, Li J, Wang Z, et al. [Applying a stage of behaviors change model on nutrition intervention in farmers]. Wei Sheng Yan Jiu 2010;39:719-22. [Article in Chinese]

16. Moradi M HA, Babaei GR, Jahangiri M. Review processes of change on resistance skills and drug abuse among petrochemical workers: application of TTM in education. Conference on health promotion and Workplace Safety. Healthy working Quarterly; Year II. 2009;7:61-70.

17. Dunn KI, Mohr P, Wilson CJ, Wittert GA. Determinants of fast-food consumption. An application of the theory of planned behaviour. Appetite 2011;57:349-57.

18. Tavafian S, AT, Zare Sh. [Distribution of smokers by stages of change of smoking: a population based study from BndarAbbass, Iran]. Payesh Journal 2009;8:263-9.

19. Dunn AL, Marcus BH, Kampert JB, et al. Reduction in cardiovascular disease risk factors: 6-month results from ProjectActive. Prev Med 1997;26:883-92.

20. Mullan BA, Wong CL. Hygienic food handling behaviours. An application of the theory of planned behaviour. Appetite 2009;52:757-61.

21. Araoye MO. Research methodology with statistics for health and social sciences. Ilorin: Nathadex Publisher. 2003;115.

22. Mahmudi A, Tajedini F, Ranjbar H, Moghimi-Dehkordi B. Determinants of overweight and obesity in the middle school students of Pakdasht city, Tehran province. J Kermanshah Univ Med Sci 2014;18:329-38.

23. Ajzen I. Constructing a TPB questionnaire: Conceptual and methodological considerations. 2002. Available from: http://www.uni-bielefeld.de/ikg/zick/ajzen $\% 20$ construction $\%$ $20 \mathrm{a} \% 20 \mathrm{tpb} \% 20$ questionnaire.pdf

24. Polit DF, Beck CT, Owen SV. Is the CVI an acceptable indicator of content validity? Appraisal and recommendations. Res Nurs Health 2007;30:459-67.

25. McArthur LH, Pawlak R. An exploratory study of compliance with dietary recommendations among college students majoring in health-related disciplines: application of the transtheoretical model. Nutr Res Pract 2011;5:578-84.

26. Ounpuu S, Woolcott D, Rossi S. Self-efficacy as an intemediate outcome variable in transtheoretical model: application to dietary fat reduction. J Nutr Educ Behav 1999;31:1-7.

27. Prochaska J, Redding C, Evers K, et al. Health behavior and health education: theory, research, and practice. The transtheoretical model and stages of change. 2002:60-84.

28. Armitage CJ, Conner M. Efficacy of the theory of planned behaviour: a meta $\square$ analytic review. Br J Soc Psychol 2001;40:471-99.

29. Clayton DA, Griffith CJ. Efficacy of an extended theory of 
planned behaviour model for predicting caterers' hand hygiene practices. Int J Environ Health Res 2008;18:83-98.

30. Latimer AE, Martin Ginis KA. The importance of subjective normsfor people who care what others think of them. Psychol Health 2005;20:53-62.

31. Hussein RAEH. Can knowledge alone predict vegetable and fruit consumption among adolescents? A transtheoretical model perspective. J Egypt Publ Health Assoc 2011;86:95103.

32. Jiang G, Li J, Wang Z, et al. [Applying a stage of behaviors change model on nutrition intervention in farmers]. Wei Sheng Yan Jiu 2010;39:719-22. [Article in Japanese]
33. Hussein RAEH. Socioeconomic status and dietary habits as predictors of home breakfast skipping in young women. J Egypt Publ Health Assoc 2014;89:100-4.

34. Farmanbar R, Niknami S, Lubans DR, Hidarnia A. Predicting exercise behaviour in Iranian college students: utility of an integrated model of health behaviour based on the transtheoretical model and self-determination theory. Health Educ J 2013;72:56-69.

35. Fallon EA, Hausenblas HA, Nigg CR. The transtheoretical model and exercise adherence: examining construct associations in later stages of change. Psychol Sport Exerc 2005;6:629-41. 